\title{
Mass Spectrometry-Based Thermal Shift Assay for Protein-Ligand Binding Analysis
}

\author{
Graham M. West, ${ }^{\dagger}$ J. Will Thompson, ${ }^{\ddagger}$ Erik J. Soderblom, ${ }^{\ddagger}$ Laura G. Dubois, ${ }^{\ddagger}$ \\ Patrick D. DeArmond, ${ }^{\dagger}$ M. Arthur Moseley, ${ }^{\ddagger}$ and Michael C. Fitzgerald ${ }^{\star,+}$
}

\author{
Department of Chemistry, Duke University, Durham, North Carolina 27708, and Institute for Genome Science and \\ Policy, Duke University Medical Center, Durham, North Carolina 27708
}

Described here is a mass spectrometry-based screening assay for the detection of protein-ligand binding interactions in multicomponent protein mixtures. The assay utilizes an oxidation labeling protocol that involves using hydrogen peroxide to selectively oxidize methionine residues in proteins in order to probe the solvent accessibility of these residues as a function of temperature. The extent to which methionine residues in a protein are oxidized after specified reaction times at a range of temperatures is determined in a MALDI analysis of the intact proteins and/or an LC-MS analysis of tryptic peptide fragments generated after the oxidation reaction is quenched. Ultimately, the mass spectral data is used to construct thermal denaturation curves for the detected proteins. In this proof-of-principle work, the protocol is applied to a four-protein model mixture comprised of ubiquitin, ribonuclease A (RNaseA), cyclophilin A (CypA), and bovine carbonic anhydrase II (BCAII). The new protocol's ability to detect protein-ligand binding interactions by comparing thermal denaturation data obtained in the absence and in the presence of ligand is demonstrated using cyclosporin A (CsA) as a test ligand. The known binding interaction between CsA and CypA was detected using both the MALDI- and LC-MS-based readouts described here.

Few analytical strategies exist for the solution phase analysis of protein-ligand binding interactions in multicomponent protein mixtures. A large majority of the more general protein-ligand binding strategies that have been developed to date rely on calorimetric or spectroscopic methods, which are only amenable to the analysis of highly purified proteins. ${ }^{1-6}$ Currently, the most widely used methods for protein-ligand binding analysis in complex mixtures involve affinity-based technologies such as protein complex purification techniques and surface plasmon

\footnotetext{
* Corresponding author. Dr. Michael C. Fitzgerald, Department of Chemistry, Box 90346, Duke University, Durham, NC 27708-0346. Phone: 919-660-1547. Fax: 919-660-1605.

${ }^{\dagger}$ Department of Chemistry.

* Institute for Genome Science and Policy.

(1) Brandts, J. F.; Lin, L. N. Biochemistry 1990, 29, 6927-6940.

(2) Hill, J. J.; Royer, C. A. Methods Enzymol. 1997, 278, 390-416.

(3) Sigurskjold, B. W. Anal. Biochem. 2000, 277, 260-266.

(4) Straume, M.; Freire, E. Anal. Biochem. 1992, 203, 259-268.

(5) Xie, D.; Gulnik, S.; Erickson, J. W. J. Am. Chem. Soc. 2000, 122, 1153311534.

(6) Robertson, A. D.; Murphy, K. P. Chem. Rev. 1997, 97, 1251-1268.
}

resonance (SPR) approaches coupled with mass spectrometry. ${ }^{7-9}$ A drawback to these affinity-based technologies is that they require the ligand to be immobilized on a solid support, which can interfere with binding. It can also be difficult to immobilize certain ligand classes (e.g., small drug molecules) on the necessary solid supports. Several affinity-based methods for proteinligand binding analysis have been developed that do not require ligand immobilization. ${ }^{10,11}$ While the generality of these methods with respect to ligand class is good, they are best suited for highthroughput screening applications where the goal is to characterize the binding of multiple ligands to a target protein and not to characterize the binding of a target ligand to multiple proteins.

More recently, several H/D exchange- and mass spectrometrybased protocols have been demonstrated for the analysis of a wide variety of different protein-ligand binding interactions. ${ }^{12-14}$ In theory the mass spectrometry-based readout in these protocols, which typically involve probing the $\mathrm{H} / \mathrm{D}$ exchange behavior of proteins as a function of time, ${ }^{12}$ concentration of chemical denaturant, ${ }^{13}$ or concentration of ligand, ${ }^{14}$ is amenable to the analysis of protein-ligand binding in multicomponent protein mixtures. In practice, the ability of these H/D exchange-based techniques to analyze proteins in very complex mixtures (e.g., cell lysates) is often limited by signal suppression issues and the resolving power of modern mass spectrometers. The most common approach for overcoming such signal suppression and resolution issues involves the use of fractionation strategies. Unfortunately, many fractionation strategies (e.g., gel electrophoresis and multidimensional chromatography) are not compatible with amide H/D exchange (i.e., they cannot be performed under conditions that preserve the protein's deuterated state).

(7) Aebersold, R.; Mann, M. Nature 2003, 422, 198-207.

(8) Ravanat, C.; Wurtz, V.; Ohlmann, P.; Fichter, M.; Cazenave, J. P.; VanDorsselaer, A.; Lanza, F.; Gachet, C. Anal. Biochem. 2009, 386, 237-243.

(9) Zhukov, A.; Schurenberg, M.; Jansson, O.; Areskoug, D.; Buijs, J. J. Biomol. Tech. 2004, 15, 112-119.

(10) Annis, D. A.; Athanasopoulos, J.; Curran, P. J.; Felsch, J. S.; Kalghatgi, K.; Lee, W. H.; Nash, H. M.; Orminati, J. P. A.; Rosner, K. E.; Shipps, G. W.; Thaddupathy, G. R. A.; Tyler, A. N.; Vilenchik, L.; Wagner, C. R.; Wintner, E. A. Int. J. Mass Spectrom. 2004, 238, 77-83.

(11) Zhao, Y. Z.; vanBreemen, R. B.; Nikolic, D.; Huang, C. R.; Woodbury, C. P.; Schilling, A.; Venton, D. L. J. Med. Chem. 1997, 40, 4006-4012.

(12) Chalmers, M. J.; Busby, S. A.; Pascal, B. D.; He, Y.; Hendrickson, C. L.; Marshall, A. G.; Griffin, P. R. Anal. Chem. 2006, 78, 1005-1014.

(13) Powell, K. D.; Ghaemmaghami, S.; Wang, M. Z.; Ma, L.; Oas, T. G.; Fitzgerald, M. C. J. Am. Chem. Soc. 2002, 124, 10256-10257.

(14) Zhu, M. M.; Rempel, D. L.; Du, Z.; Gross, M. L. J. Am. Chem. Soc. 2003, $125,5252-5253$. 
Covalent labeling protocols using chemical modifications that are more stable under standard chromatography conditions for peptide and protein analyses have also been developed. Chemical modification reactions involving protein amino acid side chains and the hydroxyl radical have been used in combination with LC-MS based peptide-mapping and sequencing experiments to probe the binding interfaces and conformational properties of protein-ligand complexes. ${ }^{15-17}$ Recently, we described a chemical modification- and mass spectrometry-based technique, termed stability of proteins from rates of oxidation (SPROX), that utilizes the hydrogen peroxide mediated oxidation of methionine side chains to ascertain conformational information about proteins in solution at various concentrations of a chemical denaturant such as guanidinium chloride $(\mathrm{GdmCl}) .{ }^{18}$ The SPROX methodology utilizes the chemical-denaturant-dependent oxidation rates of methionine residues in a protein to report on the thermodynamic properties of its global and/or subglobal unfolding/refolding reactions.

The thermal shift assay described here also utilizes the oxidation rates of methionine residues in a protein to report on the thermodynamic properties of its global and/or subglobal unfolding/refolding reactions. However, instead of probing the hydrogen peroxide mediated oxidation of methionine residues as a function of chemical denaturant concentration, the oxidation reaction is probed as a function of temperature. The so-called thermal SPROX protocol developed here is designed to follow the thermal denaturation of proteins and detect the shift in a protein's melting temperature that typically occurs upon ligand binding. The thermal SPROX technique is analogous to previously reported spectroscopy-based methods that have also taken advantage of this thermal shift to detect ligand binding interactions. ${ }^{19-21}$

A thermal SPROX protocol has potential advantages over the chemical denaturant-based SPROX protocol we initially reported. ${ }^{18}$ Chemical denaturants can suppress ionization in the MALDI and ESI analysis of proteins and peptides in complex mixtures. Chemical denaturants can also adversely affect the quality of chromatographic separation. While purification protocols exist for the removal of chemical denaturants from protein and peptide samples, they often result in a loss of protein or peptide analyte. There are also cases where denaturants can inhibit ligand binding ${ }^{22}$ and/or stabilize partially folded intermediate states that can lead to non-two-state unfolding/refolding, which complicates ligand binding analyses by SPROX.$^{18}$ A thermal SPROX protocol promises to expand the scope of protein-ligand binding interactions amenable to SPROX analyses and to facilitate applications of SPROX to proteomic samples, in which some proteins may have

(15) Guan, J. Q.; Chance, M. R. Trends Biochem. Sci. 2005, 30, 583-592.

(16) Fitzgerald, M. C.; West, G. M. J. Am. Soc. Mass Spectrom. 2009, 20, 11931206.

(17) Takamoto, K.; Chance, M. R. Annu. Rev. Biophys. Biomol. Struct. 2006, 35, 251-276.

(18) West, G. M.; Tang, L.; Fitzgerald, M. C. Anal. Chem. 2008, 80, 41754185.

(19) Epps, D. E.; Sarver, R. W.; Rogers, J. M.; Herberg, J. T.; Tomich, P. K. Anal. Biochem. 2001, 292, 40-50.

(20) Poklar, N.; Lah, J.; Salobir, M.; Macek, P.; Vesnaver, G. Biochemistry 1997, 36, 14345-14352.

(21) Pantoliano, M. W.; Petrella, E. C.; Kwasnoski, J. D.; Lobanov, V. S.; Myslik, J.; Graf, E.; Carver, T.; Asel, E.; Springer, B. A.; Lane, P.; Salemme, F. R. J. Biomol. Screen. 2001, 6, 429-440.

(22) Ma, L.; Fitzgerald, M. C. Chem. Biol. 2003, 10, 1205-1213. two-state thermal melting transitions and not two-state chemical denaturant-induced unfolding transitions.

In this work a thermal SPROX protocol is developed and tested on a four-protein model mixture consisting of ubiquitin, ribonuclease A (RNaseA), bovine carbonic anhydrase II (BCAII), and cyclophilin A (CypA). The new protocol's ability to detect a known protein-ligand interaction, the cyclosporin A (CsA) interaction with the protein $\mathrm{CypA}$, is demonstrated using two different readouts including a MALDI-TOF readout of the intact proteins and a one-dimensional LC-MS-based proteomics readout of tryptic peptides.

\section{EXPERIMENTAL SECTION}

Materials. Ubiquitin (Ubq), ribonuclease A (RNaseA), bovine carbonic anhydrase II (BCAII) from bovine erythrocytes (88 wt $\%)$, sinapinic acid (SA), sodium hydrogenphosphate, and acetonitrile were purchased from Sigma-Aldrich. Trifluoroacetic acid (TFA) was from Halocarbon. Cyclosporin A (CsA) was purchased from LKT Laboratories, Inc. Hydrogen peroxide $\left(\mathrm{H}_{2} \mathrm{O}_{2}\right) \quad(30 \%$ w/w) was purchased from SigmaAldrich. Guanidinium chloride $(\mathrm{GdmCl})$, omnipur, was from EMD Chemicals. L-Methionine (98+\% pure) was from Acros Organics. Sodium phosphate was purchased from Mallinckrodt. Zip-Tips were purchased from Millipore. Bovine serum albumin (BSA) and Coomassie Brilliant Blue G-250 dye were purchased from Bio-Rad. The cyclophilin A (CypA) (human) used in this work was obtained by recombinant DNA methods outlined previously. ${ }^{18}$

Instrumentation. MALDI mass spectra were acquired on an UltraFlex II TOF/TOF (Bruker Daltonics, Inc., Billerica, MA) mass spectrometer in the linear and positive ion mode using a smartbeam Nd:YAG laser (355 nm). Spectra were collected using the following instrument parameters: $25 \mathrm{kV}$ ion source 1 voltage, $23.4 \mathrm{kV}$ ion source 2 voltage, $6 \mathrm{kV}$ lense voltage, $100-130 \mathrm{~ns}$ pulsed ion extraction, and matrix gating to $3000 \mathrm{Da}$. Solution $\mathrm{pH}$ measurements were made using a Jenco $6072 \mathrm{pH}$ meter equipped with a Futura calomel $\mathrm{pH}$ electrode from Beckman Instruments (Fullerton, CA). The LC-MS analyses were done on a Synapt HDMS system (Waters) coupled to a nanoAcquity UPLC (Waters).

Thermal SPROX Protocol Using MALDI Readout of Intact Proteins. Two sample solutions of the four-protein model mixture were prepared and analyzed by the thermal SPROX protocol using the MALDI readout. One sample solution contained only the proteins and was comprised of $2 \mu \mathrm{M}$ Ubq, $2 \mu \mathrm{M}$ RNaseA, $2 \mu \mathrm{M}$ BCAII, and $8 \mu \mathrm{M}$ CypA in $16 \mathrm{mM}$ phosphate buffer, $\mathrm{pH} 7.4$, containing $4 \mathrm{mM}$ Tris-HCl. The other sample solution contained the proteins (at the same concentrations and buffer composition noted above), $2.2 \mathrm{mM} \mathrm{CsA}$, and 10\% DMSO. For the thermal SPROX analyses, $9 \mu \mathrm{L}$ aliquots of the above two samples were equilibrated for $15 \mathrm{~min}$ at a series of temperatures including 25 , $40,45,50,60$, and $80{ }^{\circ} \mathrm{C}$. The oxidation reaction at each temperature was initiated with the addition of $1 \mu \mathrm{L}$ of $2 \mathrm{M} \mathrm{H}_{2} \mathrm{O}_{2}$ to give a final $\mathrm{H}_{2} \mathrm{O}_{2}$ concentration of $200 \mathrm{mM}$ in the oxidation reactions. The oxidation reactions proceeded for different times depending on the temperature. The specific times used in the $25,40,45,50,60$, and $80{ }^{\circ} \mathrm{C}$ reactions were $1238,168,152$, 108,76 , and $24 \mathrm{~s}$, respectively. These oxidation reaction times corresponded to five half-lives of the oxidation reaction of an unprotected methionine residue at each temperature (see 
Oxidation Rate Determinations). After the specified reaction time at each temperature, $20 \mu \mathrm{L}$ of a $300 \mathrm{mM}$ methionine solution was added to each reaction to quench the $\mathrm{H}_{2} \mathrm{O}_{2}$, and the protein samples in each buffer were analyzed by MALDI-TOF mass spectrometry to determine the extent of protein oxidation.

Ten MALDI mass spectra were acquired for the protein samples at each temperature, and ten different weighted mass average values, mass $\mathrm{wt}_{\mathrm{w}, \mathrm{av}}$, were obtained from the ion signals of the unoxidized and oxidized proteins detected in each spectra (as previously described ${ }^{18}$ ). The mass wt,av $_{\text {values calculated in }}$ this work were calculated using a window of the mass spectrum that included the $m / z$ values expected for the wild-type ion signal and all the expected oxidation products. The weighted average change in mass, $\Delta$ mass $_{\mathrm{wt}, \mathrm{av}}$, values used in this work were calculated by subtracting the molecular weight of the unoxidized protein from the mass $_{\mathrm{wt}, \mathrm{av}}$ value. Ultimately, 10 $\Delta$ mass $_{\mathrm{wt,av}}$ values were recorded at each temperature, the values were averaged, and the averaged values were plotted versus the temperature.

Thermal SPROX Protocol Using LC-MS Readout of Proteolytic Peptide Fragments. Two sample solutions of the four-protein model mixture were prepared and analyzed by the thermal SPROX protocol using the LC-MS readout. One sample solution contained only the proteins and was comprised of $33 \mu \mathrm{M}$ Ubq, $29 \mu \mathrm{M}$ RNaseA, $35 \mu \mathrm{M}$ BCAII, and $37 \mu \mathrm{M}$ CypA in $15 \mathrm{mM}$ Tris- $\mathrm{HCl} \mathrm{pH}$ 7.4, containing $3.5 \mathrm{mM}$ phoshphate and 10\% DMSO. The other sample solution was identical to the above solution except that it also contained $1.0 \mathrm{mM}$ CsA. For the thermal SPROX analyses, $5 \mu \mathrm{L}$ aliquots of the above two samples were combined with $30 \mu \mathrm{L}$ of a $20 \mathrm{mM}$ phosphate buffer ( $\mathrm{pH}$ 7.4) and equilibrated for $15 \mathrm{~min}$ at a series of temperatures including 25, 35, 40, 42, 45, $47,50,55,60$, and $70{ }^{\circ} \mathrm{C}$. The oxidation reaction at each temperature was initiated with the addition of $5 \mu \mathrm{L}$ of $0.8 \mathrm{M} \mathrm{H}_{2} \mathrm{O}_{2}$ to give a final $\mathrm{H}_{2} \mathrm{O}_{2}$ concentration of $100 \mathrm{mM}$ in the oxidation reactions. The oxidation reactions were allowed to proceed for different times depending on the temperature. The specific times used in the $25,35,40,42,45,47,50,55,60$, and $70{ }^{\circ} \mathrm{C}$ reactions were $2476,348,330,321,305,292,271,229,182$, and $98 \mathrm{~s}$, respectively. These oxidation reaction times corresponded to five half-lives of the oxidation reaction of an unprotected methionine residue at each temperature (see Oxidation Rate Determinations). After the specified reaction time at each temperature, $80 \mu \mathrm{L}$ of a $300 \mathrm{mM}$ methionine solution was added to each reaction to quench the $\mathrm{H}_{2} \mathrm{O}_{2}$.

The samples were cooled to room temperature, centrifuged briefly ( $\sim 10 \mathrm{~s})$, and precipitated with trichloroacetic acid (TCA). TCA precipitation was initiated by adding $30 \mu \mathrm{L}$ of a TCA solution $(1 \mathrm{~g} / \mathrm{mL})$ to each $80 \mu \mathrm{L}$ protein sample. Samples were placed on ice for $30 \mathrm{~min}$ and centrifuged at $20000 \mathrm{rcf}$ for $10 \mathrm{~min}$ at $4{ }^{\circ} \mathrm{C}$ in order to pellet the proteins. The supernatant was removed with a pipet and each protein pellet was gently rinsed three times with $0.5 \mathrm{~mL}$ of ice-cold ethanol in order to remove residual TCA. Samples were left open to air for $5 \mathrm{~min}$ to facilitate evaporation of any residual ethanol.

Each protein sample was redissolved in $55 \mu \mathrm{L}$ of $50 \mathrm{mM}$ ammonium bicarbonate buffer $(\mathrm{pH} 8.5)$ containing $0.1 \%$ Rapigest. The samples were heated at $40{ }^{\circ} \mathrm{C}$ for $10 \mathrm{~min}$ to facilitate dissolution of the protein pellet. A $23 \mu \mathrm{L}$ aliquot of each sample was removed in order to quantify the amount of protein in each sample using the Bradford assay according to the procedures outlined in the Bio-Rad Quick Start kit. Bovine serum albumin (BSA) was used as the protein standard.

The remaining $32 \mu \mathrm{L}$ of each protein sample was prepared for LC-MS analysis. A total of $3 \mu \mathrm{L}$ of $100 \mathrm{mM}$ DTT in $50 \mathrm{mM}$ ammonium bicarbonate ( $\mathrm{pH}$ 8.5) was added to each solution. The samples were heated at $80^{\circ} \mathrm{C}$ while shaking for $15 \mathrm{~min}$, cooled at room temperature for $5 \mathrm{~min}$, briefly centrifuged $(\sim 10 \mathrm{~s})$, and 3.5 $\mu \mathrm{L}$ of $200 \mathrm{mM}$ IDA in $50 \mathrm{mM}$ ammonium bicarbonate (pH 8.5) was added to each sample. Samples were incubated in the dark at room temperature for $30 \mathrm{~min}$. A $1 \mu \mathrm{L}$ aliquot of trypsin $(0.1$ $\mu \mathrm{g} / \mu \mathrm{L}$ in $50 \mathrm{mM}$ ammonium bicarbonate, $\mathrm{pH} 8.5$ ) was added to each sample to give a 1:30 ratio of trypsin-protein $(w / w)$. The samples were digested with trypsin overnight at $37{ }^{\circ} \mathrm{C}$ while shaking. The Rapigest was cleaved by adding $1.5 \mu \mathrm{L}$ of $50 \%$ TFA and $1 \mu \mathrm{L}$ of $\mathrm{MeCN}$ and shaking the samples for $2 \mathrm{~h}$ at $60{ }^{\circ} \mathrm{C}$. The samples were centrifuged at $15000 \mathrm{rcf}$ for $5 \mathrm{~min}$ to ensure that the samples were free from particulates, prior to LC-MS analysis.

For the LC-MS analyses, $200 \mathrm{fmol}$ of total protein per sample was injected on the column, which was a $75 \mu \mathrm{m} \times 150 \mathrm{~mm}$ Acquity BEH C18 column. Approximately $200 \mathrm{fmol}$ of a pooled control sample that consisted of equal aliquots of each of the 20 thermal SPROX samples was initially subjected to an LC-MS/MS analysis. This pooled sample was analyzed in a data-dependent acquisition (DDA) scan sampling the top three most intense precursor ions for mass integration at $\sim 1 \mathrm{~Hz}$. The raw data in this DDA experiment were processed using Mascot Distiller (Matrix Sciences, Ltd.) and searched with Mascot v2.2 (Matrix Sciences, Ltd.) against the Swissprot v57.2 database. The search parameters were carbamidomethyl (on Cys residues) as a fixed modification, oxidation (on Met residues) as a variable modification, trypsin enzyme specificity, $20 \mathrm{ppm}$, and precursor and 0.04 Da product ion mass accuracy. Peptides were annotated if they had a Mascot score $>35$, which was the Identity Score $(p<0.05)$ for the database search parameters. False discovery rate was assessed using a search against a decoy database (full $1 \mathrm{X}$ random coverage); this result returned no hits for a $0 \%$ false discovery rate. In a separate search, carbamidomethylation of Cys was set as a variable modification and both oxidation and dioxidation of Cys and Met was allowed, in order to assess overoxidation under the treatment conditions. No new peptides were identified with a Mascot score $>35$.

Following the analysis of the pooled sample, $200 \mathrm{fmols}$ of total protein in the 20 thermal SPROX samples were analyzed in a dataindependent acquisition (DIA). These DIA runs were acquired in MSE mode using alternating scans of $0.9 \mathrm{~s}$ at a collision energy of $6 \mathrm{~V}$ and $0.9 \mathrm{~s}$ with a 15-40 $\mathrm{V}$ collision energy ramp. All runs were analyzed using a gradient of $5-40 \%$ mobile phase B over 30 min, with a flow rate of $400 \mathrm{~nL} / \mathrm{min}$ at $55{ }^{\circ} \mathrm{C}$. Mobile phases A and $\mathrm{B}$ used for the separation were $0.1 \%$ formic acid in water and $0.1 \%$ formic acid in acetonitrile, respectively.

The data was aligned and peaks were quantified using Rosetta Elucidator v3.3. Individual groups were assigned for each treatment condition. Peaks were aligned based on accurate mass and retention time allowing the translation of identifications from the DDA ions to the DIA ions. Data was aligned using Peak Teller in the Rosetta software (Rosetta Biosoftware Inc.). Label-free peptide 


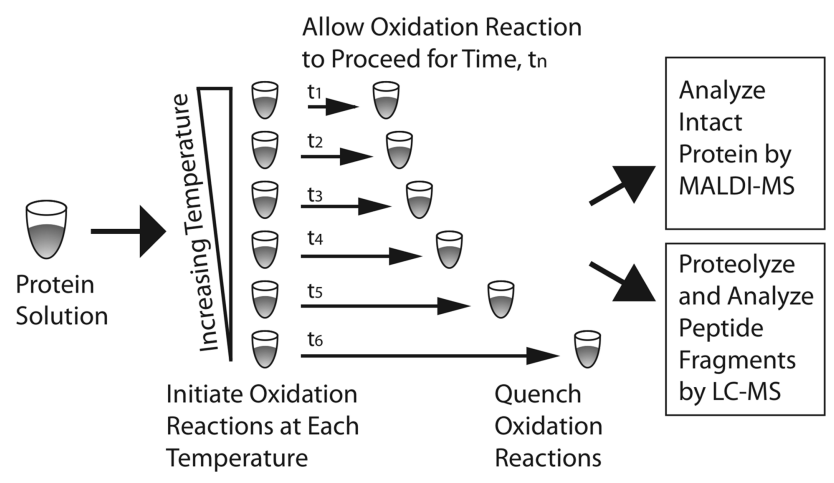

Figure 1. Schematic representation of the thermal SPROX protocol developed in this work.

quantitation was performed using an area under the curve approach. Peak intensities were extracted from the data using the Rosetta software.

Oxidiation Rate Determinations. Second-order rate constants for the $\mathrm{H}_{2} \mathrm{O}_{2}$ oxidation of unprotected methionine sites in an amino acid sequence were experimentally determined at six temperatures between 40 and $90^{\circ} \mathrm{C}$. In each experiment, a $50 \mu \mathrm{M}$ solution of a model methionine-containing peptide, substance $\mathrm{P}$, was prepared in $20 \mathrm{mM}$ sodium phosphate, $\mathrm{pH}$ 7.4. Substance $P$ is an 11 amino acid peptide with one $\mathrm{N}$-terminal methionine residue. The oxidation reactions were carried out in the presence of $150 \mathrm{mM} \mathrm{H}_{2} \mathrm{O}_{2}$ at $40{ }^{\circ} \mathrm{C}$, in the presence of $15 \mathrm{mM} \mathrm{H}_{2} \mathrm{O}_{2}$ at 50,60 , and $70{ }^{\circ} \mathrm{C}$ and in the presence of $5 \mathrm{mM} \mathrm{H}_{2} \mathrm{O}_{2}$ at 80 and $90{ }^{\circ} \mathrm{C}$. The $\mathrm{H}_{2} \mathrm{O}_{2}$ concentration was reduced at the higher temperatures to slow the reaction rate to the point that conversion to oxidation products could be easily monitored by MALDI-TOF mass spectrometry. The extent of oxidation was followed by plotting the $\Delta$ mass $_{\mathrm{wt} \text {,av }}$ values obtained from the MALDI analysis of substance $\mathrm{P}$ at each time point versus oxidation time. The data in the $\Delta$ mass $_{\mathrm{wt}, \mathrm{av}}$ vs time plots were fit to the single exponential function given in eq 1 ,

$$
\Delta \text { mass }_{\mathrm{wt}, \mathrm{avg}}=Y_{0}+B\left(1-\mathrm{e}^{-(c) \dagger}\right)
$$

where $Y_{0}$ is the $y$-intercept, $B$ is a measure of the amplitude, $(c)$ is the pseudo-first-order rate constant, and $t$ is time. The pseudo-first-order rate constants determined for substance $\mathrm{P}$ at each temperature were divided by the $\mathrm{H}_{2} \mathrm{O}_{2}$ concentrations used in each experiment (i.e., 5,15 , or $150 \mathrm{mM}$ ) to generate a second-order rate constant for the oxidation of methionine in an unstructured peptide sequence. The second-order rate constants determined here were fit to the Arrhenius equation, eq 2 .

$$
\ln k=-\left(\frac{E_{\mathrm{a}}}{R}\right)\left(\frac{1}{T}\right)+\ln A
$$

In eq $2, A$ is the prefactor and $E_{\mathrm{a}}$ is the activation energy, $R$ is the ideal gas constant, and $T$ is the temperature in Kelvin.

\section{RESULTS AND DISCUSSION}

Protocol Development. The experimental protocol developed here (Figure 1) involves reacting equal aliquots of a protein sample
Table 1. Summary of Kinetic Parameters Obtained in This Work for the Hydrogen Peroxide Mediated Oxidation of the Single Methionine Residue in Substance $P$ at Different Temperatures in $20 \mathrm{mM}$ Sodium Phosphate Buffer, pH 7.4

\begin{tabular}{cc}
$\begin{array}{c}\text { temperature } \\
\left({ }^{\circ} \mathrm{C}\right)\end{array}$ & {$\left[\mathrm{H}_{2} \mathrm{O}_{2}\right](\mathrm{mM})$} \\
40 & 150 \\
40 & 15 \\
50 & 15 \\
60 & 15 \\
70 & 15 \\
80 & 5 \\
90 & 5 \\
\hline
\end{tabular}

$\begin{array}{cc}\begin{array}{c}\text { pseudo-first-order } \\ \text { rate constant, } \\ k\left(\mathrm{~h}^{-1}\right)\end{array} & \begin{array}{c}\text { second-order rate } \\ \text { constant, } k_{\text {ox }} \\ \left(\mathrm{M}^{-1} \mathrm{~h}^{-1}\right)\end{array} \\ 50.0 & 333 \\ 6.12 & 408 \\ 8.64 & 576 \\ 12.2 & 813 \\ 23.0 & 1530 \\ 13.0 & 2600 \\ 35.6 & 7120\end{array}$

\section{Table 2. Summary of the Second-Order Rate Constants Used to Calculate the Oxidation Reactions Times Used in the Thermal SPROX Experiments Described Here $^{a}$}

$\begin{array}{cccc}\begin{array}{c}\text { second-order } \\ \text { temperature } \\ \left({ }^{\circ} \mathrm{C}\right)\end{array} & \begin{array}{c}100 \mathrm{mM} \mathrm{H}_{2} \mathrm{O}_{2}{ }^{b} \\ \text { rate constant, } \\ k_{\text {ox }}\left(\mathrm{M}^{-1} \mathrm{~h}^{-1}\right)\end{array} & \begin{array}{c}200 \mathrm{mM} \mathrm{H}_{2} \mathrm{O}_{2}{ }^{c} \\ \text { time }(\mathrm{s})\end{array} & \begin{array}{c}\text { half-life time } \\ (\mathrm{s})\end{array} \\ 25 & 50.4^{d} & 2476 & 1238 \\ 35 & 356^{e} & 348 & \\ 40 & 371^{f g} & & 168 \\ & 378^{e} & 330 & \\ 42 & 389^{e} & 321 & 152 \\ 45 & 410^{e} & 305 & \\ 47 & 428^{e} & 292 & \\ 50 & 576^{f} & & \\ & 461^{e} & 271 & \\ 55 & 547^{e} & 229 & \\ 60 & 813^{f} & & \\ 70 & 684^{e} & 182 & \\ & 1530^{f} & & \\ 80 & 1278^{e} & 98 & \\ 90 & 2600^{f} & & \end{array}$

${ }^{a}$ The second-order rate constants are those determined for the $\mathrm{H}_{2} \mathrm{O}_{2}$-mediated oxidation of an unprotected methionine residue. ${ }^{b}$ Concentration of $\mathrm{H}_{2} \mathrm{O}_{2}$ used in the thermal SPROX experiment with MALDI readout. ${ }^{c}$ Concentration of $\mathrm{H}_{2} \mathrm{O}_{2}$ used in the thermal SPROX experiment with $\mathrm{LC}-\mathrm{MS}$ readout. ${ }^{d}$ Experimentally determined value from ref $18 .{ }^{e}$ Interpolated value from plot in Figure $2 \mathrm{~A}^{f}$ Experimentally determined value from Table $1 .{ }^{g}$ Average of the two experimental values reported in Table 1.

with hydrogen peroxide at a range of different temperatures. The same amount of hydrogen peroxide is reacted with the protein samples at each temperature, but the specific reaction time is varied according to the temperature. The oxidation reaction time at each temperature is set such that the oxidation reaction at each temperature proceeds for a time equivalent to five half-lives of the oxidation reaction of an unprotected methionine residue at that temperature. The oxidation times used here were determined using the kinetic parameters measured in our oxidation studies of the unprotected methionine side chain in substance P (see Tables 1 and 2). The times were relatively long for samples oxidized at the lower temperatures (e.g., several thousand seconds at room temperature) and relatively short for samples oxidized at higher temperatures (e.g., $24 \mathrm{~s}$ at $80^{\circ} \mathrm{C}$ ). The five half-live oxidation time used in this work was long enough to ensure the quantitative oxidation of methionine side chains in an unstructured protein and short enough to keep oxidation times at higher 

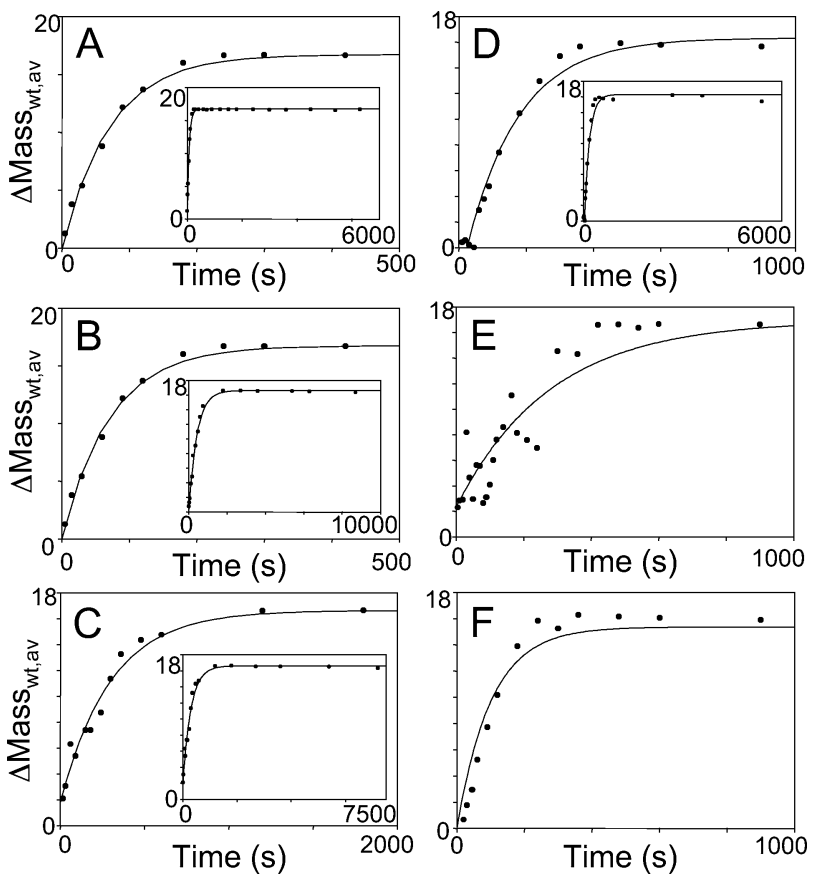

Figure 2. Data obtained in the oxidation rate determination experiments. The time course of the $\mathrm{H}_{2} \mathrm{O}_{2}$-mediated oxidation of the methionine side chain in substance $P$ was measured at $40,50,60$, 70,80 , and $90^{\circ} \mathrm{C}$ in parts $\mathrm{A}, \mathrm{B}, \mathrm{C}, \mathrm{D}, \mathrm{E}$, and $\mathrm{F}$, respectively. The lines represent the best fit of each data set to eq 1 using a nonlinear least-squares analysis. The pseudo-first-order rate constants determined from each data set are summarized in Table 1.

temperatures within a practically achievable limit (i.e., $>20$ s) and to minimize oxidation at sites other than methionine residues. Most important for the ligand binding analyses was that the same oxidation time was used for the sample pairs (i.e., the samples with and without ligand) at a given temperature.

In theory, the oxidation times could be held constant in a thermal SPROX experiment and the $\mathrm{H}_{2} \mathrm{O}_{2}$ concentration could be adjusted. For example, if a constant 5 min oxidation time were used, the $\left[\mathrm{H}_{2} \mathrm{O}_{2}\right]$ range for temperatures from 25 to $80{ }^{\circ} \mathrm{C}$ would be 825 to $16 \mathrm{mM}$. In this approach, care must be taken to choose $\mathrm{H}_{2} \mathrm{O}_{2}$ concentrations in large excess of protein concentration to ensure pseudo-first-order kinetics. The thermal SPROX protocol outlined in Figure 1 (constant $\left[\mathrm{H}_{2} \mathrm{O}_{2}\right]$ with variable time) was employed in this proof-of-principle work. However, in theory, both approaches should produce equivalent results if the $\left[\mathrm{H}_{2} \mathrm{O}_{2}\right]$ and time are tuned such that the oxidation reactions for unprotected methionine residues are allowed to proceed for the same number of half-lives.

The first step in the development of the thermal SPROX protocol was to determine the temperature dependence of the rate constant associated with the $\mathrm{H}_{2} \mathrm{O}_{2}$ mediated oxidation reaction of an unprotected methionine residue. To this end, second order rate constants for the $\mathrm{H}_{2} \mathrm{O}_{2}$ mediated oxidation of a single unprotected methionine residue in a model peptide, substance $\mathrm{P}$, were experimentally determined at six temperatures ranging from 40 to $90{ }^{\circ} \mathrm{C}$ (see Table 1). Ultimately, the second-order rate constants, which were calculated using pseudo-first-order rate constants measured at these temperatures (see Figure 2 and Table 1 ), were plotted as a function of temperature (see Figure 3 ). The
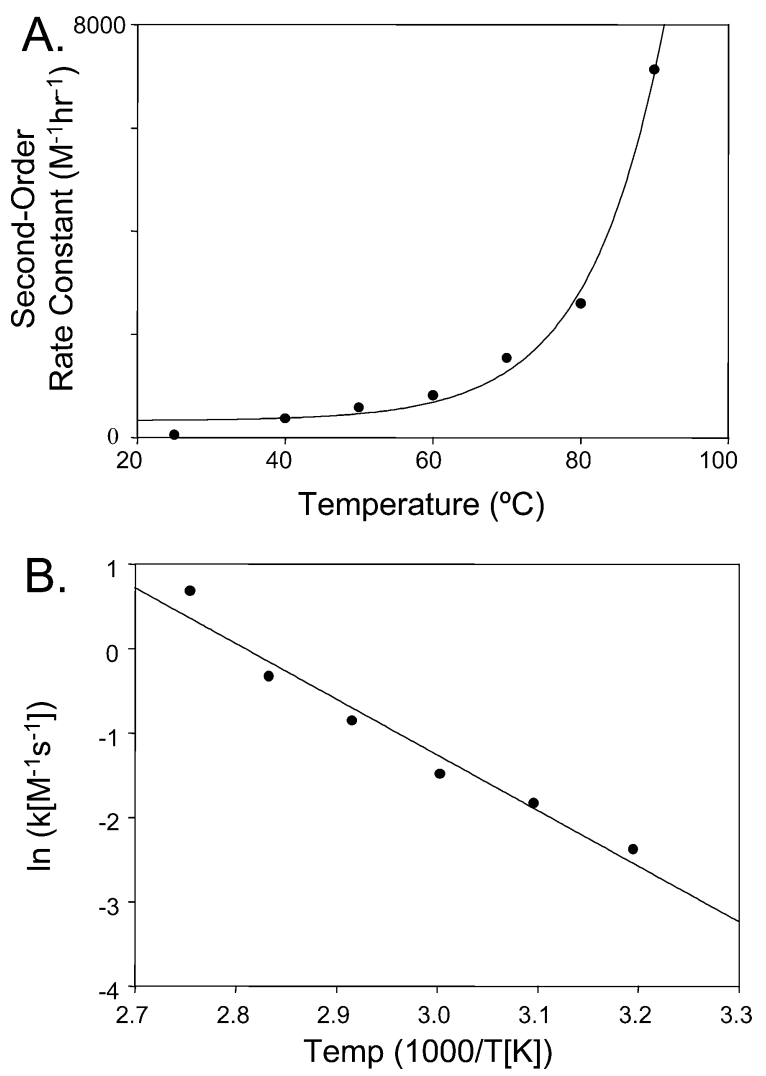

Figure 3. Temperature dependence of the second-order rate constant for the hydrogen peroxide mediated oxidation of the unprotected methionine residue in substance $P$. The data in part $A$ include all the experimentally determined second-order rate constants in Table 2, and the line in part A represents the best fit of the data to a three parameter exponential equation, $Y=Y_{0}+a e^{\mathrm{bx}}$, which was used to obtain the interpolated values reported in Table 2. The interpolated values were obtained using $Y_{0}, a$, and $b$, values of 327 , 0.992 , and 0.0981 , respectively. The data in part $B$ include the only experimentally determined second-order rate constants in this work (see Table 2), and the line in part B represents the best fit of the data to the Arrhenius equation (eq 2) using a linear least-squares analysis.

data were fit to the Arrhenius equation (eq 2) to evaluate a preexponential factor, $A$, and an activation energy, $E_{\mathrm{a}}$, for the $\mathrm{H}_{2} \mathrm{O}_{2}$ mediated oxidation of an unprotected methionine residue (Figure 3B).

The $A$ and $E_{\text {a }}$ parameters determined here for the oxidation of unprotected methionine side chain in substance $\mathrm{P}$ were 1.13 $\times 10^{8} \mathrm{M}^{-1} \mathrm{~s}^{-1}$ and $13.1 \mathrm{kcal} / \mathrm{mol}$, respectively. Such parameters have been reported in the literature for the hydrogen peroxide mediated oxidaton of unprotected methionine residues in other peptides. ${ }^{23}$ The $A$ and $E_{\text {a }}$ parameters reported for three peptides in ref 23 ranged from $7.94 \times 10^{5}$ to $2.0 \times 10^{6} \mathrm{M}^{-1} \mathrm{~s}^{-1}$ and $10.8-11.3 \mathrm{kcal} / \mathrm{mol}$, respectively. The differences between the values determined here and those reported by Pan and coworkers ${ }^{23}$ are likely due to differences in the reaction conditions (e.g., buffer composition and $\mathrm{pH}$ ). The experimental conditions used in this oxidation rate study (i.e., $20 \mathrm{mM}$ phosphate buffer, $\mathrm{pH}$ 7.4) were chosen to match the conditions used in the thermal SPROX experiments and not those in ref $^{23}$ (i.e., $10 \mathrm{mM}$ sodium acetate buffer, $\mathrm{pH}$ 4.0).

(23) Pan, B.; Abel, J.; Ricci, M. S.; Brems, D. N.; Wang, D. I.; Trout, B. L. Biochemistry 2006, 45, 15430-15443. 
In our development and application of the thermal SPROX protocol, it was assumed that the protein oxidation reaction was exclusively mediated by hydrogen peroxide and not by more highly reactive hydroxyl free radicals. The UV light-induced degradation of hydrogen peroxide to form hydroxyl free radicals is temperature dependent; ${ }^{24}$ therefore, it is possible that the increased oxidation rates observed at higher temperatures were due, in part, to increased concentrations of hydroxyl free radicals that may have formed from stray room light. However, two lines of evidence suggest the contribution of hydroxyl free radical oxidation in our experiments was small. One line of evidence comes from the observation that the temperature dependence of the second order rate constants determined here for the hydrogen peroxide mediated oxidation reaction of substance $P$ were wellfit to the Arrhenius equation (see Figure 3B). The second line of evidence is related to the oxidation reaction products detected in our mass spectral analysis of the pooled control sample, which contained aliquots of each of the 20 thermal SPROX samples. In particular, only singly oxidized methionine residues were detected in the LC-MS analysis. Reaction products expected from the hydroxyl free radical reaction (e.g., methionine oxidation to the sulfone and cysteine side chain oxidation) were not detected.

Analysis of a Model Protein Mixture: Intact Protein Readout. The thermal SPROX protocol outlined above was used to analyze a four-protein model mixture containing Ubq, RNaseA, CypA, and BCA. With the use of a MALDI readout of the intact proteins, it was possible to detect ion signals for three out of the four proteins in the mixture including Ubq, RNaseA, and CypA. The absence of MALDI ion signals for BCAII, which was presumably due to signal suppression effects, precluded the thermal SPROX analysis of this protein using the MALDI-readout. Shown in Figure 4 are the thermal SPROX data for Ubq, RNaseA, and CypA, acquired using the MALDI readout. Representative MALDI mass spectra obtained in these analyses are shown in Figure SI-1 in the Supporting Information.

The $\Delta$ mass $_{\mathrm{wt}, \mathrm{av}}$ values obtained for Ubq were relatively constant (i.e., within experimental error) at the different temperatures (see Figure 4A) and all significantly lower than those expected for unfolded Ubq (i.e., $\sim 16 \mathrm{Da}$ ), which only has a single methionine in its sequence. These results suggest that the Ubq was not thermally denatured at any of the temperatures used in this work and that the melting temperature for Ubq at $\mathrm{pH} 7.4$ is above $80^{\circ} \mathrm{C}$. This is consistent with thermal denaturation studies of Ubq where the protein has been shown to have a $T_{\mathrm{m}}$ of $>90{ }^{\circ} \mathrm{C}$ at $\mathrm{pH} 7.4 .^{25}$

Thermal melting transitions were observed in the SPROX data obtained for RNaseA (Figure 4B) and CypA (Figure 4C). As expected for a protein that does not bind CsA, the $\Delta$ mass $_{\mathrm{wt}, \mathrm{av}}$ values obtained for RNaseA in absence and in the absence of ligand were within experimental error at each temperature. The $T_{\mathrm{m}}$ values obtained for RNaseA in the presence and absence of ligand, 52 and $54{ }^{\circ} \mathrm{C}$, respectively, were also within the experimental error $\left( \pm 2{ }^{\circ} \mathrm{C}\right)$. In contrast to the RNaseA data, the $T_{\mathrm{m}}$ values obtained for CypA in the absence and presence of ligand (Figure 4C) were different, 43 and $49^{\circ} \mathrm{C}$. As expected, the thermal melting transition of CypA was shifted to a higher

(24) Chu, L.; Anastasio, C. J. Phys. Chem. A 2005, 109, 6264-6271.

(25) Wintrode, P. L.; Makhatadze, G. I.; Privalov, P. L. Proteins 1994, 18, 246253.

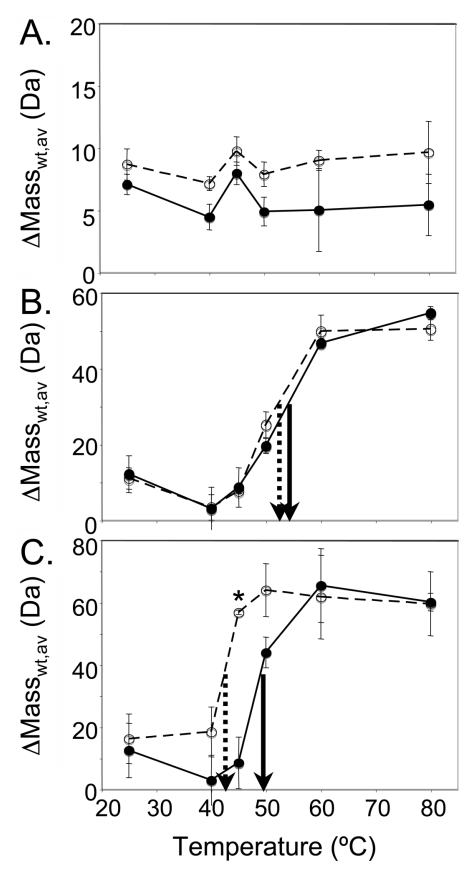

Figure 4. Thermal SPROX data obtained on the four-protein model mixture using a MALDI readout. Shown in parts $A, B$, and $C$ are the data obtained for Ubq, RNaseA, and CypA, respectively, both in the presence (closed symbols) and absence (open symbols) of CsA. The data points collected in the absence and presence of CsA are connected by dotted and solid lines, respectively. The arrows denote the $T_{\mathrm{m}}$ values of each data set estimated by visual inspection. The * symbol denotes temperatures at which a significant difference is observed between the $\Delta M_{\mathrm{wt}, \mathrm{av}}$ values obtained in the presence and absence of CsA. The data points and error bars represent the average and standard deviation associated with 10 replicated measurements. The error bars are consistent with the expected mass accuracy of the MALDI-TOF $(0.1-0.5 \mathrm{ppt})$.

temperature in the presence of $\mathrm{CsA}$, a known tight binding ligand of CypA. ${ }^{26-28}$ The thermal melting transition shift in the case of CypA is clearly observed due to the marked difference in $\Delta$ mass $_{\mathrm{wtav}}$ values obtained for CypA in the absence and in the presence of CsA at $45{ }^{\circ} \mathrm{C}$.

Analysis of a Model Protein Mixture: LC-MS-Based Proteomics Readout. The four-protein model mixture was also subjected to the thermal SPROX protocol using an LC-MS-based readout of proteolytic peptides. After the thermal SPROX samples were quenched, they were prepared for the LC-MS-based readout in the same way that protein samples are typically processed in LC-MS-based proteomics analyses. The oxidized protein samples obtained at each temperature were precipitated with TCA, redissolved in buffer, reduced, alkylated, digested with trypsin, and each sample was submitted to an LC-MS analysis to identify and quantitate the nonoxidized and oxidized methionine containing peptides in each sample.

Initially, a pooled sample containing material from each SPROX buffer was submitted to an LC-MS analysis in order to determine the methionine-containing peptide coverage of each protein. A total

(26) Handschumacher, R. E.; Harding, M. W.; Rice, J.; Drugge, R. J.; Speicher, D. W. Science 1984, 226, 544-547.

(27) Harding, M. W.; Handschumacher, R. E. Transplantation 1988, 46, 29S$35 \mathrm{~S}$.

(28) Liu, J.; Farmer, J. D., Jr.; Lane, W. S.; Friedman, J.; Weissman, I.; Schreiber, S. L. Cell 1991, $66,807-815$. 
of 45 tryptic peptides were sequenced and successfully mapped to one of the four proteins (17 mapped to CypA with $81 \%$ sequence coverage, 21 mapped to BCAII with $63 \%$ sequence coverage, 6 mapped to RNaseA with $18 \%$ sequence coverage, and 1 mapped to Ubq with $17 \%$ sequence coverage). Of the 45 tryptic peptides sequenced in the analysis of the pooled sample, 20 were methionine-containing peptides. Of these 20 methionine-containing peptides, four were identified in oxidized and unoxidized forms. These four peptides included three from CypA (including CypA(1-19), CypA(132-144), and CypA(56-69)) and one from BCA (BCA(226250)).

The identification of methionine-containing peptides in their oxidized and unoxidized forms was important for the generation of thermal SPROX data using the LC-MS readout, because the extent of oxidation at each temperature was determined by quantifying the relative amounts of nonoxidized and oxidized methionine containing peptides at each temperature. The nature of the LC-MS readout (i.e., the fact that methionine containing peptides do not generally coelute with their oxidation products) did not permit the evaluation of $\Delta$ mass $_{\text {wt,av }}$ values from a single mass spectrum as was done in the MALDI readout. Rather, peak areas from extracted ion chromatograms of the oxidized and nonoxidized methionine containing peptides were used to evaluate a fraction-oxidized value for each methionine-containing peptide at each temperature.

Shown in Figure 5 are thermal SPROX data obtained for the four methionine-containing peptides highlighted above. The fraction-oxidized values obtained for the CypA(1-19) peptide (Figure 5A) of sequence MVNPTVFFDIAVDGEPLGR were close to 1 and relatively constant across all the temperatures. There was also little difference between the values obtained with and without CsA. The absence of a melting transition and the predominance of oxidized material at all temperatures suggest that the methionine residue in this peptide is in a solvent accessible region of the CypA three-dimensional structure. This is consistent with NMR data ${ }^{29}$ that suggests this methionine side chain is in a solvent exposed region in the folded structure of CypA.

The fraction-oxidized values obtained for the CypA(132-144) peptide (Figure 5B) of sequence VKEGMNIVEAMER transitioned from $\sim 0.1$ at the lower temperatures to $\sim 0.6$ at the higher temperatures. The detection of a melting transition for this peptide using Met-142 as a probe indicates that the Met-142 side chain in this peptide is located in a buried region of the protein's threedimensional structure that becomes exposed to solvent as the protein thermally unfolds. There are also significant differences in the thermal SPROX data obtained with and without ligand at temperatures 45,47 , and $50^{\circ} \mathrm{C}$. The differences at these temperatures are due to a shift in the melting temperature of the protein when it is alone and when it is complexed with CsA. The observed shift in the melting transition is indicative of CsA binding.

It is noteworthy that X-ray crystallographic data available on the CypA-CsA complex ${ }^{30}$ shows that the methionine residues in the CypA(132-144) peptide are removed from the binding site. The melting temperature shift detected for the CypA(132-144) peptide must result in the increased global stability of the protein

(29) Ottiger, M.; Zerbe, O.; Guntert, P.; Wuthrich, K. J. Mol. Biol. 1997, 272, 64-81.

(30) Mikol, V.; Kallen, J.; Pflugl, G.; Walkinshaw, M. D. J. Mol. Biol. 1993, 234, 1119-1130.

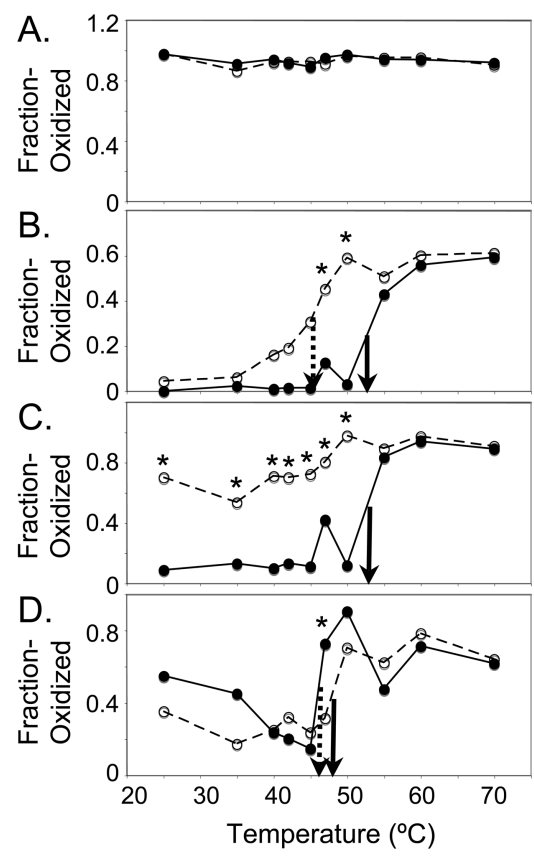

Figure 5. Thermal SPROX data obtained on the four-protein model mixture using an LC-MS readout of tryptic peptides. (A) Data obtained on the CypA(1-19) peptide of sequence MVNPTVFFDIAVDGEPLGR using the oxidized and unoxidized forms of Met-1. (B) Data obtained on the CypA(132-144) peptide of sequence VKEGMNIVEAMER, using the oxidized and unoxidized forms of Met-142. The Met-136 residue was unoxidized and the Asn side-chain was deamidated in both the oxidized and unoxidized VKEGMNIVEAMER peptide ions used to probe the Met-142 oxidation reaction. (C) Data obtained for the CypA(56-69) peptide of sequence IIPGFMCQGGDFTR using the oxidized and unoxidized forms of Met-61. (D) Data obtained for the BCAII(226-250) peptide of sequence TLNFNAEGEPELLMLANWRPAQPLK using the oxidized and unoxidized forms of Met-239. The open and closed symbols represent the results from analyses performed in the absence and presence, respectively, of CsA. The data points collected in the absence and presence of CsA are connected by dotted and solid lines, respectively. The arrows denote the $T_{\mathrm{m}}$ values of each data set estimated by visual inspection. The * symbol denotes temperatures with significant differences between the fraction-oxidized values obtained in the presence and absence of CsA.

when it is complexed with CsA. These results highlight the fact that useful methionine containing peptides for the peptide readout in thermal SPROX need not be derived from regions directly involved in binding. Rather, they can be derived from any globally protected (i.e., solvent inaccessible) region of the folding domain(s) in the protein that are involved in ligand binding. In theory, the temperature dependent oxidation of Met-136 in the CypA(132-144) peptide could produce a melting transition similar to that obtained for Met-142. However, such a curve could not be constructed from the data collected in this work, as the appropriate pair of peptides (i.e., the oxidized and unoxidized Met-136 form of CypA(132-144)) was not identified in the LC-MS analysis of the pooled sample that was used for peptide and protein identification. The oxidized Met-136 product was not identified, presumably because it was not selected for MS/MS in this DDA analysis.

The fraction-oxidized values obtained for the CypA(56-69) peptide (Figure 5C) of sequence IIPGFMCQGGDFTR in the absence of ligand were close to 1 and relatively constant across all the temperatures. However, in the presence of CsA, the 
Table 3. Thermal Melting Transitions ( $T_{m}$ Values)

Observed for the Model Proteins Detected in This Study in the Presence and Absence of CsAa

\begin{tabular}{|c|c|c|}
\hline protein & $T_{\mathrm{m}}\left({ }^{\circ} \mathrm{C}\right)(-) \mathrm{CsA}$ & $T_{\mathrm{m}}\left({ }^{\circ} \mathrm{C}\right)(+) \mathrm{CsA}$ \\
\hline ubiquitin (intact) $^{d}$ & $>80(90)^{b}$ & $>80$ \\
\hline RNaseA (intact) ${ }^{d}$ & $52(58-64)^{c}$ & 54 \\
\hline CypA (intact) ${ }^{d}$ & 43 & 49 \\
\hline $\operatorname{CypA}(1-19)^{e}$ & $\mathrm{NT}^{f}$ & $\mathrm{NT}^{f}$ \\
\hline $\operatorname{CypA}(132-144)^{e}$ & 45 & 52 \\
\hline $\operatorname{CypA}(56-69)^{e}$ & $\mathrm{NT}^{f}$ & 52 \\
\hline BCAII (intact) ${ }^{d}$ & $\mathrm{ND}^{g}$ & $\mathrm{ND}^{g}$ \\
\hline $\operatorname{BCAII}(226-250)^{e}$ & 46 & 48 \\
\hline
\end{tabular}

${ }^{a}$ Estimated error for all measurement was approximately $\pm 2{ }^{\circ} \mathrm{C}$. ${ }^{b}$ Values from ref 25. ${ }^{c}$ Values from refs 31 and $32 .{ }^{d}$ Data obtained using MALDI-TOF readout of intact protein. ${ }^{e}$ Data obtained using LC-MS readout of indicated tryptic fragment. ${ }^{f} \mathrm{NT}$, no transition observed. ${ }^{g} \mathrm{ND}$, not detected in mass spectral readout.

fraction-oxidized values CypA(56-69) follow a pattern similar to that observed for the $\mathrm{CypA}(132-144)$ peptide analyzed in the presence of CsA (Figure 5B). The consistently low fractionoxidized values for CypA(56-69) obtained at $25-50{ }^{\circ} \mathrm{C}$ indicate that the methionine side chain in this peptide is protected from solvent in the CypA-CsA complex, either from a conformational change in CypA or a direct effect of being located in the binding pocket. X-ray crystallographic data available for CypA and the CypA-CsA complex ${ }^{30}$ indicate that the Met-61 side chain is indeed buried in the CsA binding pocket.

Melting transitions could also be ascertained from fractionoxidized values obtained for the BCA(226-250) peptide of sequence TLNFNAEGEPELLMLANWRPAQPLK (Figure 5D). There was more scatter in the pre- and post-transition regions of the data obtained for this peptide (potentially due to the low ion signal intensities observed for this peptide). However, a transition region between 45 and $50{ }^{\circ} \mathrm{C}$ is evident (Figure 5D). Moreover, there was only a small different in the position of the melting transitions recorded in the absence and presence of ligand. The small difference of $2{ }^{\circ} \mathrm{C}$ was within the experimental error of the $T_{\mathrm{m}}$ values determinations (see Table 3 ), and it is consistent with that expected for a protein that has no known interactions with CsA.

One potential complication with the $\mathrm{LC}-\mathrm{MS}$-based readout is that the protein samples from the SPROX buffers are susceptible to background oxidation during the multiple steps (i.e., reduction, alkylation, and proteolysis) that are needed for LC-MS sample preparation. As we have previously noted in conventional SPROX analyses, ${ }^{18}$ small amounts of oxidation before and/or after the hydrogen peroxide treatment do not interfere with the analysis. All samples in a SPROX experiment are equally susceptible to such background oxidation. Thus any background oxidation will be similar in all the samples and not contribute to the denaturant dependence in conventional SPROX or the temperature dependence in thermal SPROX.

Thermal Melting Transition Characterization. The thermal denaturation data generated in the thermal SPROX experiment is directly analogous to thermal denaturation data generated in optical spectroscopy-based methods. ${ }^{19-21}$ In theory, the same

(31) Arnold, U.; Ulbrich-Hofmann, R. Biochemistry 1997, 36, 2166-2172.

(32) Navon, A.; Ittah, V.; Laity, J. H.; Scheraga, H. A.; Haas, E.; Gussakovsky, E. E. Biochemistry 2001, 40, 93-104. equations used to extract thermodynamic parameters (e.g., $T_{\mathrm{m}}$, $\Delta C_{\mathrm{p}}, \Delta H$, and $K_{\mathrm{d}}$ ) from thermal denaturation curves generated in optical spectroscopy-based experiments could be used to extract such parameters from the thermal denaturation curves generated in the thermal SPROX experiment. In practice, we found there were not enough data points in our thermal SPROX curves to generate all of the above thermodynamic parameters with reasonable fitting errors. The $T_{\mathrm{m}}$ value was the only parameter that could be reasonably extracted from the thermal SPROX curves. Visual inspection of the curves recorded in this work produced $T_{\mathrm{m}}$ values with uncertainties of approximately $2{ }^{\circ} \mathrm{C}$ (see Table 3 ). In general, the uncertainty associated with the $T_{\mathrm{m}}$ value of a thermal SPROX curve will be determined by the number of data points collected in a protein's melting transition region and by the cooperativity of the thermal unfolding transition, which is ultimately defined by the biophysical properties of the protein-folding reaction.

Thermal melting transitions have previously been reported for two of the model proteins in this work, ubiquitin and RNaseA. The thermal SPROX data obtained on ubiquitin are consistent with that reported in the literature. ${ }^{25}$ However, the $T_{\mathrm{m}}$ estimated from the thermal SPROX data obtained on RNaseA is slightly smaller than that obtained in traditional thermal melting experiments (see Table 3 ). This smaller $T_{\mathrm{m}}$ value may be a result of the methionine oxidation reaction in thermal SPROX destabilizing the folded three-dimensional structure of RNaseA, something which we have previously noted in the SPROX analysis of RNaseA. $^{18}$

Thermal SPROX $T_{\mathrm{m}}$ values are expected to be some degree lower than $T_{\mathrm{m}}$ values measured in spectroscopy-based experiments, even in the absence of any potential perturbations introduced by the oxidation reaction. This is because the covalent labeling reaction in the thermal SPROX experiment marks proteins that have undergone repeated unfolding/ refolding events and acquired label at a specific temperature as opposed to marking the actual fraction of unfolded protein at a given temperature. Ultimately, the temperature dependence of the protein folding free energy (i.e., the cooperativity of the thermal denaturation curve) will determine the degree to which $T_{\mathrm{m}}$ values derived from thermal SPROX experiments are shifted relative to those derived in spectroscopy-based experiments. Proteins with more cooperative thermal denaturation curves will yield $T_{\mathrm{m}}$ values in the thermal SPROX experiment that more closely match those in spectroscopy-based experiments.

The extraction other thermodynamic parameters such as $\Delta C_{\mathrm{p}}$, $\Delta H$, and $K_{\mathrm{d}}$ values from thermal SPROX might be possible if a large number of data are collected. However, the inherent uncertainties in the two mass spectral readouts described here (i.e., the accuracy of protein molecular weight measurements by MALDI-TOF, and the quantitative capabilities of LC-MS experiments) are still likely to limit the precision with which such parameters can be determined in the thermal SPROX experiment. Moreover, the time required to perform the number of mass spectral analyses that would be needed to appropriately fit the data (i.e., on the order of 50 analyses) would be excessively long in the case of the $\mathrm{LC}-\mathrm{MS}$ readout. However, it is important to emphasize that the thermal SPROX data collected here, which included 6-10 data points/curve, 
was sufficient to generate $T_{\mathrm{m}}$ values to within several degrees, and this was adequate protein for the qualitative analyses of ligand binding described below.

Qualitative Analysis of Protein-Ligand Binding. The primary motivation for developing the thermal SPROX protocol was to detect protein-ligand binding interactions. This requires the acquisition of thermal SPROX data in the absence and in the presence of ligand, and then a comparison of the data to determine if the $T_{\mathrm{m}}$ value was shifted. A $T_{\mathrm{m}}$ value shift of $6{ }^{\circ} \mathrm{C}$ was detected for the intact CypA analysis using the MALDI readout (Figure $4 \mathrm{C}$ ), and a similar $T_{\mathrm{m}}$ value shift of $7{ }^{\circ} \mathrm{C}$ was detected for the CypA(132-144) peptide using the LC-MS readout (Figure 5B). Such an increased $T_{\mathrm{m}}$ value is expected for a protein that directly interacts with the target ligand. For proteins like CypA that fold and unfold in a concerted manner, the $T_{\mathrm{m}}$ value shift observed for the intact protein is expected to be similar to the $T_{\mathrm{m}}$ value shift observed for peptide fragments containing globally protected methionine residues. However, $T_{\mathrm{m}}$ values recorded for methionine-containing peptides detected the LC-MS-based proteomics readout may not always be the same as that measured for the intact protein. In the case of large multidomain proteins that do not unfold/refold in a concerted manner, the methionine-containing peptide detected in the LC-MS readout will report on the subglobal unfolding properties of the protein domain from which they originated. Thus, in cases where the different domains in a protein have different stabilities, different $T_{\mathrm{m}}$ values will be recorded.

The $T_{\mathrm{m}}$ value shifts detected in ligand binding analyses using thermal SPROX do not always have to be to higher temperature. For example, in the analysis of a complex protein mixture, it is possible that a direct binding interaction between one protein and the target ligand could either induce and/or preclude the interaction of one protein to a second protein. In the case of a precluded interaction, one would expect a destabilization of the involved proteins leading to a thermal transition shift to lower temperatures. Similarly, in the analysis of large multidomain proteins, a ligand binding event to one protein domain might result in the destabilization of a second protein domain and thus produce a thermal transition shift to lower temperatures when methionine-containing peptides from the second protein domain are probed.

In ideal cases, the $T_{\mathrm{m}}$ values recorded in thermal shift assays can be used to evaluate binding constants. Ideal cases include those in which the protein unfolding reaction is two-state and reversible. A common issue with thermal shift assays (whether they involve a calorimetric, optical, or mass spectral readout) is that the thermal denaturation of many proteins is not reversible because heat denatured proteins often form folding incompetent aggregates. ${ }^{21}$ Indeed, the thermal denaturation of the four proteins analyzed here was not reversible. Protein samples incubated for $15 \mathrm{~min}$ at $80^{\circ} \mathrm{C}$ did not generate the expected oxidation reaction products when they were cooled to room temperature and oxidized. However, meaningful thermodynamic parameters associated with protein folding and ligand binding are frequently extracted from thermal shift data by assuming the aggregation process is slow compared to the rates of protein folding and unfolding. ${ }^{21}$
The calculation of binding constants from $T_{\mathrm{m}}$ value shifts requires prior knowledge/evaluation of $\Delta H$ and $\Delta C_{\mathrm{p}}$ values for the protein folding reaction (see eq SI-1 in the Supporting Information). Unfortunately, the limited number of data points in thermal SPROX curves precluded the evaluation of such thermodynamic parameters in our experiments. Given the relatively small number of data points that are likely to be generated in thermal SPROX experiments, the technique will likely be limited to the semiquantitative analyses of ligand binding based on $T_{\mathrm{m}}$ value shifts. Moreover, it is clear that the technique will be most sensitive to ligand binding if the highest possible ligand concentrations are employed. This is because the $T_{\mathrm{m}}$ value shift measured in a thermal shift assay is not only a function of $\Delta H$ and $\Delta C_{\mathrm{p}}$ but also the ligand concentration (see eq SI- 1 in the Supporting Information). In more conventional thermal shift assays, ligand concentrations of $50-100 \mu \mathrm{M}$ (and at least 10-fold excess over the protein concentration) have been shown to produce $T_{\mathrm{m}}$ value shifts of $1-10^{\circ} \mathrm{C}$ for ligands with $K_{\mathrm{d}}$ values ranging from high millimolar to low nanomolar. ${ }^{21}$ Considering the $T_{\mathrm{m}}$ value uncertainties in this work (see Table 3 ), protein-ligand binding interactions with $K_{\mathrm{d}}$ values at the lower end of this range are likely to be most amenable to analysis by the thermal SPROX technique.

\section{CONCLUSIONS}

The thermal SPROX technique developed here is expected to be a useful protein-ligand binding discovery tool. This technique is compatible with MALDI and LC-MS based proteomics platforms and could in theory be used to screen for protein-ligand binding interactions in biological mixtures as complicated as cell lysates. The technique's two main caveats are that the oxidation reaction not preclude the binding interaction and that the appropriate ion signals for the target proteins be detected in the mass spectrometry readout. For example, in the LC-MS-based proteomics readout only proteins identified with unoxidized and oxidized methionine-containing peptides will be amenable to analysis. In the proof-of-principle experiments described here two of the four proteins in the model mixture were successfully analyzed in the LC-MS-based proteomics readout and three out of the four proteins were successfully analyzed in the MALDI readout of the intact proteins. Thermal denaturation data was ultimately obtained on all four model proteins in this work, and the known binding interaction of CsA with CypA was successfully detected using both the LC-MS and MALDI-based readouts described here.

\section{ACKNOWLEDGMENT}

This material is based upon work supported by the National Science Foundation under a grant to M.C.F. (Grant CHE-0848462).

\section{SUPPORTING INFORMATION AVAILABLE}

Additional information as noted in text. This material is available free of charge via the Internet at http://pubs.acs.org.

Received for review February 20, 2010. Accepted May 17, 2010.

AC100465A 